\title{
Muros como tecnologías y dispositivos territoriales de control
}

Rogério Haesbaert

Universidad Federal Fluminense, Brasil.

Recibido: 22 de diciembre de 2017. Aceptado:12 de junio de 2018.

\begin{abstract}
Resumen
Este artículo problematiza la condición aparentemente "fuera del tiempo y del espacio" de la reciente dinámica de difusión de los muros como tecnologías de control. Esta condición refleja una nueva interacción, una compleja combinación entre diferentes modalidades de control como marcas de los procesos que, en las sociedades biopolíticas o de in-seguridad contemporáneas, denominamos contención territorial. En un lenguaje foucaultiano, el "territorio-muro" es pensado no solo como una simple tecnología política sino, más bien, como un dispositivo de poder al mismo tiempo de dominación técnico-material y de apropiación simbólica.
\end{abstract}

PALABRAS CLAVE: MUROS. DISPOSITIVOS DE CONTROL. TERRITORIO. CONTENCIÓN TERRITORIAL.

\section{Walls: technologies and dispositives of territorial control}

\begin{abstract}
The recent diffusion of walls as technologies of control and its understanding as seemingly "out of time and space" condition, is discussed throughout this paper. This condition shows both a new interaction and a complex combination among different modes of control, which are traces of territorial containment of biopolitical societies. The "territory-wall", using Foucaultian concepts, is thought not only as political technology but also as a dispositive of power, of technical domination and symbolic appropriation.
\end{abstract}

KEYWORDS: WALLS. CONTROL DISPOSITIVE. TERRITORY. TERRITORIAL CONTAINMENT.

PALAVRAS-CHAVE: MUROS. DISPOSITIVOS DE CONTROLE. TERRITÓRIO. CONTENÇÃO TERRITORIAL. 


\section{Introducción}

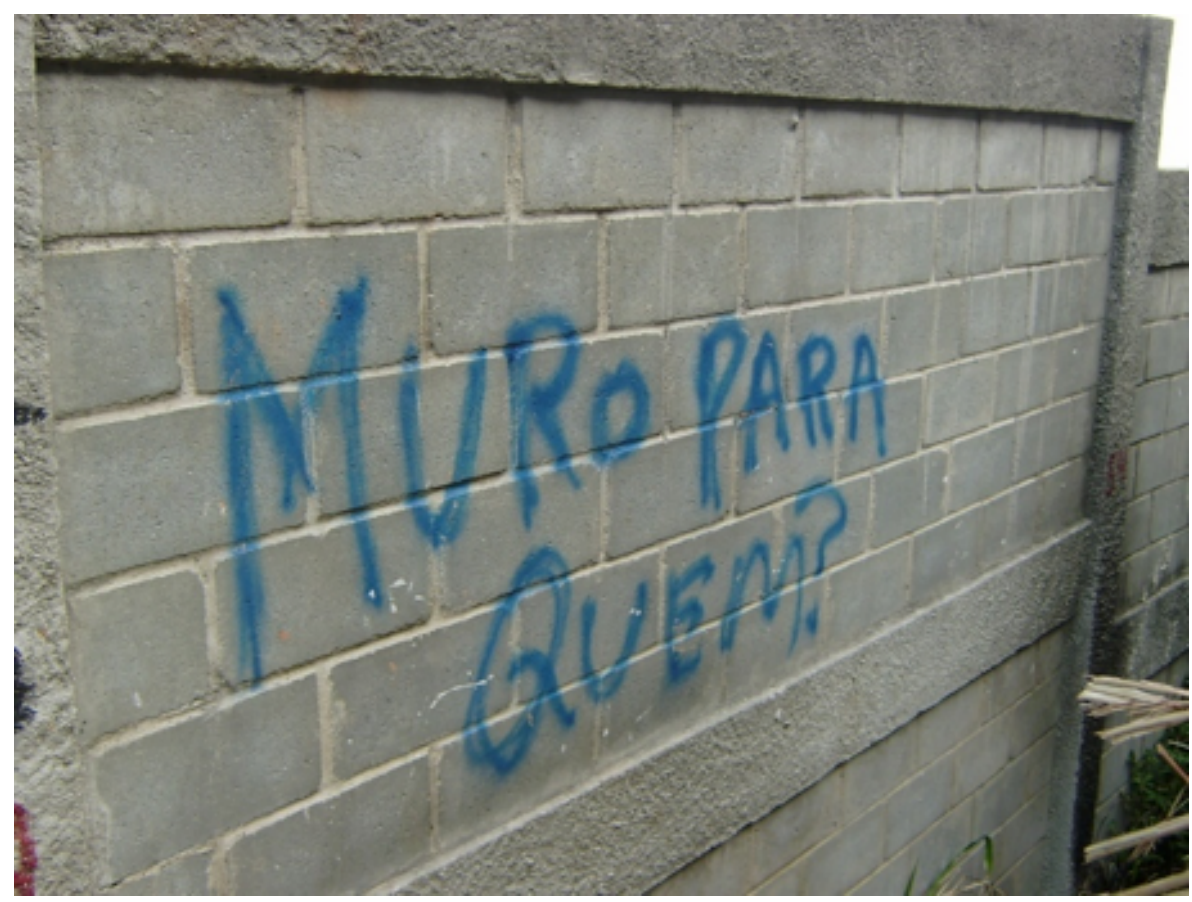

Figura 1. Muro en la favela Santa Marta, Rio de Janeiro ("Muro para quién?"). Fuente: Fotografía del autor.

En una entrevista, Michel Foucault, señalaba que no estaba a favor de la destrucción sino "de que se pueda seguir adelante y avanzar, de que los muros se puedan derribar" (Droit, 2008: 74). Esta afirmación es de extrema actualidad en un mundo en el que, en plena era de la (in) seguridad en nombre de la cual se difunden cada vez más tecnologías avanzadas vinculadas a la televigilancia, crece también el proceso que podemos llamar, de amurallamiento. Nunca en la historia tuvimos un mundo potencialmente tan móvil $\mathrm{y}$, al mismo tiempo, con un aparato tan sofisticado de monitoreo de las poblaciones y de su movilidad. De forma aparentemente paradójica, tampoco nunca tuvimos tantas murallas de gran extensión como los muros fronterizos construidos a lo largo de los últimos quince años alrededor del mundo. Este artículo problematiza la dinámica de difusión de estas tecnologías, aparentemente arcaicas, considerada como fuera del tiempo y del espacio, pero que refleja una nueva interacción, una compleja combinación entre diferentes modalidades de control que marcan nuestro tiempo.

Sin embargo, antes de ingresar de modo más directo en el análisis del amurallamiento y de las diferentes modalidades de muros que estamos construyendo, comenzaremos realizando algunas consideraciones teóricas que servirán de base para nuestras argumentaciones, principalmente en lo que se refiere al pensamiento de Michel Foucault. Sabemos que dicho autor reconoce que todas las relaciones sociales son igualmente relaciones de poder, y de un poder que involucra siempre resistencia -no como su otro, sino como inherente a estas relaciones-. Antes de leer el poder desde una perspectiva teórica, de construir una teoría del poder, opta por llevar adelante su análisis desde un punto de vista que prioriza el abordaje sobre su ejercicio, sobre sus prácticas efectivas. 
A partir de este punto de vista, Foucault se aproxima mucho a la geografía, mejor dicho, a la posición de un geógrafo. Esto quiere decir que él lee el poder no solo a través de su arqueología (el poder íntimamente vinculado a la producción de saber, a la institución de regímenes de verdad) sino también de genealogías concretas, de prácticas que involucran una temporalidad - muchas veces fragmentada- y una espacialidad, una geografía que se encuentra siempre abierta a la redefinición de tácticas y estrategias reconstruidas en función de una mayor o menor resistencia espacial en el campo de las luchas sociales. Es así que llegamos a la configuración de distintas tecnologías de poder. Una de ellas, quizás la más difundida geo-históricamente, aunque profundamente reconfigurada en sus funciones y en sus significados a lo largo del tiempo, es la del muro o, como prefiero, la de los procesos de amurallamiento que será abordada en este artículo. La amplitud de su difusión lleva a ciertos autores a identificar hasta una política específica de los muros o de barreras físicas. Es el caso de Stéphane Rosière (2015) que habla de una teicopolítica (el término teicos, significa en griego muro) que iría acompañada también de una teicoeconomía, la economía de la construcción y de la gestión de estos muros.

$\mathrm{Al}$ abordar los muros, este artículo problematiza también la producción del territorio, es decir, los procesos de des-re-territorialización a través de la construcción de distintas modalidades de murallas, una de las tecnologías o, de forma amplia, de los dispositivos territoriales de control más recurrentes a lo largo de la historia. Cabe destacar que el territorio, es visto aquí no solamente como una técnica, producto y productora de poder, sino también como una expresión simbólica de este poder. Esto exige ir un poco más allá de aquellos autores que, inspirados en Foucault, como el geógrafo Stuart Elden (2013), conciben al territorio como una tecnología de poder. Además de este carácter funcional, como veremos, la construcción de muros incluye también, y de forma cada vez más enfática, una dimensión simbólica del poder.

\section{Sobre el territorio y la desterritorialización}

La palabra territorio encuentra su origen etimológico ligado al término territorium conforme al Digesta, uno de los cuatro componentes claves del Corpus JurisCivilis, el Cuerpo de la Ley Civil del emperador Justiniano. Esta palabra fue utilizada en el marco del Imperio Romano para designar "toda tierra (o campo) comprendido en el interior de los límites de cualquier jurisdicción”. Según Elden (2013: 222), Bartolus, el comentarista de este pasaje, "hace una vinculación explícita del territorium con aquel sobre el cual la civitas ejerce fuerza militar", describiéndolo como "el poder de castigar o fijar los límites de las leyes sobre el espacio aterrorizado".

Es interesante observar aquí, como enfatiza Elden, que el territorio es más bien una propiedad del espacio que el espacio en sí mismo -la propiedad del ejercicio del poder (de la ley) por la fijación de los límites en el espacio-. Se pasa así del territorio como espacio absoluto, extensión o superficie de tierra ocupada y delimitada, al territorio como espacio relacional, inmerso en relaciones de poder que se ejercen concretamente a través del establecimiento de límites que son, al mismo tiempo, límites en el espacio y en el funcionamiento de la ley. En muchos casos, algunos muy antiguos, los muros se constituyeron en una técnica o dispositivo claro para establecer y visibilizar estos límites. Así, el territorio se convirtió en un elemento constitutivo fundamental de la 
institucionalización política. De aquí, proviene la primera gran tradición interpretativa, aquella que asocia el territorio al espacio de ejercicio del poder -o al de la soberaníaestatal.

Al mismo tiempo que se vincula a la tierra, el territorio también tiene una raíz etimológica mucho menos difundida, aquella que guarda relación con la idea de territor, verbo que significa amedrentar, aterrorizar. Por extensión, podemos decir que la delimitación de un territorio como una propiedad privada o un límite internacional, en especial entre aquellos que son cercados o amurallados, puede generar temor entre grupos privados de su acceso, así como un vínculo afectivo de seguridad e identificación (por lo menos entre aquellos que no solo ejercen su dominio, sino que efectivamente se apropian de aquel espacio).

Propongo definir al territorio, a partir de una concepción más amplia del poder, que vaya mucho más allá de la visión funcional-estatal de un poder localizado y centralizado. En cierto sentido, me inspiro en la amplia concepción de poder de Foucault -aun cuando él, al accionar la designación de territorio, lo hace solo en relación al Estado o al poder soberano-. Difundido a través de todas las relaciones sociales, en esta concepción ampliada, el poder permite que hablemos de territorio tanto cuando nos referimos a la delimitación de un supra-Estado como la Unión Europea, como cuando hablamos del control al acceso en una sala de clase. Es en este sentido, que un autor como Robert Sack (1986) define al territorio en múltiples escalas, a partir de las estrategias por las cuales se ejerce el control de los flujos, a través del control espacial de la accesibilidad.

En consecuencia, se puede afirmar que el territorio nace como categoría normativa, en tanto espacio de comando político y de extensión o de alcance de la ley. Cabe destacar que en la actualidad su conceptualización extrapola parte de esta condición jurídicopolítico normativa, en la medida en que el territorio está también difundido como categoría de la práctica, especialmente en el contexto de los movimientos sociales latinoamericanos. Su reinterpretación, como categoría analítica en el ámbito de la reflexión teórica e intelectual, no puede perder de vista el diálogo con estas otras condiciones, normativa y de la práctica (o del sentido común). Es por esto que somos llevados a observar la fuerza con que el territorio es accionado como herramienta no solo conceptual, en el sentido analítico más estricto (a fin de comprender en qué consiste nuestro espacio y cómo se organiza), sino también, cómo este se encuentra involucrado en acciones cotidianas y/o políticas más concretas.

Es en este sentido que el territorio emerge, principalmente en América Latina, no solo como producto de dominación sino también como manifestación de distintas formas culturales de apropiación, en sentido lefebvriano, involucrando una densa dimensión simbólica. A partir del caso de las poblaciones afrodescendientes de la región pacífica colombiana, algunos autores como Escobar (2015), han llegado a afirmar que el territorio es ontológicamente constitutivo de las luchas por su (r)existencia en tanto grupo cultural.

Esta dimensión simbólica de los procesos de desterritorialización, vinculada implícita o explícitamente a la cuestión de poder, tiene una larga historia en el pensamiento geográfico. Para comenzar, podemos hacer mención a los aportes de uno de los autores clásicos 
en el debate sobre el territorio, Jean Gottman. El autor proponía que, en conjunto con la estructura del poder estatal abordada tradicionalmente, la iconografía territorial asociada a los símbolos, fortalecería la construcción de los territorios.

Quizás podríamos afirmar que existe una diferencia entre las interpretaciones dominantes sobre el territorio en las realidades latinas (en el sentido de lenguas latinas) y aquellas de carácter anglosajón. Mientras que en estas últimas predomina una visión funcional o, más aun, tecnológica del territorio (como lo muestra Elden (2013) al restringir su definición del territorio a una tecnología política), las lecturas dominantes en países como Francia, Italia, España y, especialmente en toda América Latina, amplían y destacan la concepción del territorio también como espacio culturalmente construido.

De todas formas, la cuestión del poder aparece como un aspecto común que permite aproximar a estas distintas perspectivas del estudio del territorio. En todas ellas, de una manera o de otra, se pondrá énfasis en el poder desde el aspecto económico, destacándose los abordajes territoriales de autores como Milton Santos (2000 [1996]), hasta el poder simbólico (Bourdieu, 1989). Sobre esta base, elaboré una propuesta propia de concepción del territorio:

(...) puede concebirse a partir de la imbricación de múltiples relaciones de poder, del poder material [o mejor, de efectos materiales más evidentes] de las relaciones económico-políticas al poder simbólico de relaciones de orden más estrictamente cultural (Haesbaert, 2011[2004]: 68).

(...) el territorio, en términos relacionales..., es el resultado de la constitución diferenciada entre las múltiples dimensiones de ese poder, desde su naturaleza más estrictamente política hasta su carácter en rigor simbólico, pasando por las relaciones dentro del llamado poder económico, indisociables de la esfera jurídico-política (Haesbaert, 2011[2004]: 79-80).

El territorio, en su relación amplia entre el espacio y el poder, con o sin muros físicos, más estable o más fluido (ya que la repetición del movimiento, como afirman Deleuze y Guattari (1994), también nos territorializa), transita así en un continuum entre el sentido dominante del control material sobre la tierra y sus recursos, fijos y móviles, y el sentido -aunque minoritario, no menos relevante- referido al sentimiento que estos controles implican, sea de miedo, para aquellos que son apartados de su acceso, sea de confortabilidad o abrigo como diría Jean Gottman (1952, 1973), para quien saca provecho de él y a partir del cual se establecen lazos de fortalecimiento y seguridad.

Entonces, podemos afirmar que el territorio, como categoría de análisis, debe ser siempre situado dentro de una relación que se extiende desde una perspectiva más estrictamente funcional, en la materialidad de una porción del suelo o tierra delimitada (y controlada) por ejemplo, a través de un muro; hasta el abordaje más simbólico, involucrando el poder de una conciencia identitaria -un tipo de territorialidad, si deseáramos- que existe primeramente sólo en la medida en que se refiere a un espacio, sea actual o del pasado, pero que nos moviliza y empodera. En otras palabras, se trata del ir y venir entre procesos que Henri Lefebvre denominó de dominación (de carácter más abstracto ligado, por ejemplo, al valor de cambio) y de apropiación del espacio (más vinculado al valor de uso). 
Muros como tecnologías y dispositivos territoriales...

ROGÉRIO HAESBAERT

En relación a la apropiación de la ciudad por el ciudadano, Lefebvre afirma que está asociada al valor de uso y a un orden próximo, mientras que la dominación tiene que ver más con el valor de cambio y a un orden distante (Lefebvre, 1989). Cabe destacar que, en este caso, la apropiación no tiene que ver con la propiedad ya que la apropiación privada de la tierra está directamente vinculada a lo que el autor identifica como procesos de dominación, más formales, de "arriba para abajo”. Así, Lefebvre afirma:

Podemos decir que el grupo se apropia de un espacio natural modificado para servir a sus necesidades y posibilidades. La posesión (propiedad) sólo fue una condición y lo más a menudo una desviación de esta actividad "apropiativa" que alcanza su cima en la obra de arte. Un espacio apropiado parece una obra de arte, que no es lo mismo que decir que sea un simulacro. A menudo se trata de una construcción, de un monumento o de una edificación, pero no siempre es así: un sitio, una plaza o una calle pueden ser perfectamente considerados como espacios "apropiados" (2013: 213-214). ${ }^{1}$

Sin embargo, el autor sostendrá que el concepto de dominación solamente adquiere efectivamente sentido, si es contrapuesto "dialécticamente" a la idea inseparable de apropiación. Para este autor, ambos pueden y aún más deben andar juntos. Pero la historia de la acumulación "es también la historia de su separación, de su contradicción”, capitaneada por la dominación. Tal vez de una forma simplificada, Lefebvre afirma que, en muchos espacios tradicionales como en una choza, un iglú o una casa campesina, habría apropiación y no dominación. La oposición entre estos dos procesos crece, principalmente, con el papel de ejército, del Estado y del poder político. No obstante, aún con la "victoria" de la dominación, la apropiación no puede desaparecer.

Lefebvre nos permite construir varios binomios asociativos entre dominación y apropiación, que demuestran su carácter indisociable, como cantidad y calidad, diferencia inducida y diferencia producida, Logos (razón) y Eros (deseo) respectivamente. Sin embargo, en este mundo moderno capitalista, el binomio que aparece con mayor énfasis es el de valor de cambio y valor de uso. A partir de distinguir "apropiación" de "propiedad" (privada) -que asocia con dominación- Lefebvre afirma:

El uso reaparece en conflicto agudo con el cambio en el espacio porque implica "apropiación" y no "propiedad". Ahora bien, la apropiación conlleva tiempo (o tiempos), ritmo (o ritmos), símbolos y una práctica. Cuanto más funcionalizado está un espacio -cuanto más se encuentra dominado por los "agentes" que lo manipulan y lo vuelven monofuncional-, menos se presta a la apropiación. ¿Por qué? Pues porque se sitúa fuera del tiempo vivido, tiempo diversificado y complejo experimentado por los usuarios (2013: 389).

Aun cuando el término territorio aluda a una entidad estabilizada, una especie de producto, enfatizamos siempre, retomando la triada trabajada por Deleuze-Guattari (1994) y Raffestin (2013), el proceso de construcción y destrucción, o de entrada y salida, de un territorio -los procesos de des-reterritorialización-. La TDR [Territorialización-Desterritorialización-Reterritorialización] involucra de forma integrada la formación de territorios (territorialización) y su desconstrucción o la salida de ellos 
(desterritorialización), y el ingreso de otro o su reconfiguración sobre nuevas bases (reterritorialización). Como ya señalamos, sin confundir el territorio solo con su base física, debemos comprender que toda dinámica de desterritorialización puede ser vista por lo menos en dos sentidos:

El sentido general y analítico de salida y/o de destrucción de un territorio, condición que no presenta un carácter axiomático, valorativo (desterritorialización como buena o mala en sí misma);

El sentido más estricto de desterritorialización como precarización territorial (que discutimos en el libro El mito de la desterritorialización [Haesbaert, 2011]), cuando representa efectivamente la pérdida del control territorial, en particular, cuando se trata sobre todo de los grupos subalternos.

De esta manera, es fundamental distinguir siempre los sujetos, sus relaciones y el contexto histórico y social (económico, político y cultural) en que se desdobla la desterritorialización. ${ }^{2}$ Es en el sentido relacional que la lectura del territorio precisa adquirir un sentido amplio cuando, por ejemplo, este incorpora un muro, un cerco o una pared. En tanto construcción material, fija y aislada, o sea, en tanto espacio absoluto, el muro no interesa como territorio. Ahora bien, desde una perspectiva relacional, resulta interesante observar que este aparece inmerso en vínculos de poder -que deben ser vistos también como redes- que hacen de él un instrumento, una tecnología o un dispositivo (tal como se detallará en el próximo apartado) de des-territorialización. Esto puede observarse en el ejemplo al que siempre hago alusión: el del presidiario que, confinado entre las paredes de su celda, parece extremadamente bien territorializado. En verdad sucede lo contrario, su territorialización es muy precaria pues, en el conjunto de relaciones o redes de poder en el que los muros de la prisión están insertos, él no dispone del control de su espacio o de la territorialidad, en tanto carece del control de la accesibilidad, como diría Robert Sack.

\section{Las múltiples modalidades del poder y de territorios-muro en el tiempo}

Foucault nos permite trabajar las problemáticas territoriales y, por extensión, la cuestión de los muros a partir del juego entre tres modalidades de poder y de espacialidad que denominaré de territorialidad, en el sentido genérico, refiriéndome a la condición para la existencia del territorio sin que, obligatoriamente, sea efectivamente construido. Estas modalidades marcan la formación del mundo moderno-occidental de matriz europea: del poder soberano, jurídico-legal, vinculado al ordenamiento de un territorio y sus recursos; del poder disciplinar, asociado al campo individual de las normas, con el hombre visto en tanto cuerpo a ser adiestrado; y del biopoder, más directamente ligado a la cuestión de la seguridad y a la gestión de las poblaciones (el

2 Solo así no corremos el riesgo de usar el término de forma indiscriminada; como si un gran capitalista en constante movimiento entre distintas residencias alrededor del mundo fuese desterritorializado de la misma manera que un inmigrante pobre en la búsqueda de mejores condiciones de vida en tierra extranjera. Mientras que el primero, aun moviéndose está mucho más multiterritorializado y tiene pleno control sobre los diversos territorios que comparte, el segundo, aun cuando se desplace, está en la búsqueda del territorio mínimo para su sobrevivencia básica cotidiana. 
Muros como tecnologías y dispositivos territoriales... ROGÉRIO HAESBAERT

hombre visto no solo como cuerpo sino también como especie). Sin embargo, no se trata como señala Foucault (2009: 23), de una era legal, una era disciplinar y una era de seguridad, ya que identificarlas como "lo antiguo, moderno y contemporáneo" ocultaría lo esencial:

De hecho, hay una serie de edificios complejos en los cuales el cambio afectará, desde luego, las técnicas mismas que van a perfeccionarse o en todo caso a complicarse, pero lo que va a cambiar es sobre todo la dominante, o más exactamente, el sistema de correlación entre los mecanismos jurídico legales, los mecanismos disciplinarios y los mecanismos de seguridad (2009: 23).

Tendríamos así, un cambio territorial fundamentado en la mudanza de las técnicas de control a través del espacio, cuya significación se modificará profundamente a lo largo del tiempo. Foucault propondrá una distinción genérica de espacialidades/territorialidades, que se sintetiza en la siguiente afirmación: "la soberanía se ejerce en los límites de un territorio, la disciplina se ejerce sobre el cuerpo de los individuos y la seguridad, para terminar, se ejerce sobre el conjunto de la población" (2009: 27). Sin embargo, el autor afirma que este esquema no funciona, pues para todos ellos se plantea el mismo problema, el de la administración y organización de las multiplicidades que, de cierta manera y siguiendo las reflexiones de Doreen Massey (2008), son expresión de nuestra propia condición espacial.

Esta preocupación con la gestión de la multiplicidad humana involucra así, esencialmente, las estrategias de control de las disposiciones de los individuos (sobre todo en el poder disciplinario) y de la masa de la población (sobre todo en el biopoder) a través del espacio. De aquí la importancia de aquello que Foucault define como "dispositivo". Aunque muchas veces sea visto solo en una dimensión material, técnica, el dispositivo constituye una noción amplia que involucra:

(...) un conjunto decididamente heterogéneo que engloba discursos, instituciones, instalaciones arquitectónicas, decisiones reglamentarias, leyes, medidas administrativas, enunciados científicos, proposiciones filosóficas, morales, filantrópicas. En resumen, los elementos del dispositivo pertenecen tanto a lo dicho como a lo no dicho. El dispositivo es la red que se puede establecer entre estos elementos....El dispositivo se halla siempre inscripto en un juego de poder, pero también siempre ligado a uno de los bordes del saber, que nacen de él pero asimismo, lo condicionan. El dispositivo es esto: unas estrategias de relaciones de fuerza soportando unos tipos de saber y soportadas por ellos. Sin embargo...es algo mucho más general que...la episteme...es discursivo y no discursivo, sus elementos son mucho más heterogéneos (Foucault, 1985: 244).

Al retomar el debate Agamben (2014), se remonta al origen etimológico de la palabra dispositivo y luego recuerda la importancia de la dis-positio, del dis-ponere, que podemos afirmar, hace referencia a la buena disposición, al buen ordenamiento de los objetos y de los flujos en el espacio -lo cual, en los términos de Brown (2015 [2010]) está altamente relacionado con una "sociedad amurallada"-. De esta manera, Agamben definirá al dispositivo como la "capacidad de capturar, orientar, determinar, interceptar, modelar, controlar, asegurar los gestos, las conductas, las opiniones, y los discursos" (2014: 40). 
Así, el muro adquiere un papel distinto como dispositivo acoplado a un conjunto de saberes -y también de simbologías- en cada sociedad diferente, en cada momento histórico y/o modalidad de relación de poder.

A pesar de que las sociedades disciplinarias son claramente visibles a lo largo de todo el siglo XIX, Foucault sitúa en la segunda mitad del siglo XVIII en Europa, el inicio de un cambio de foco respecto a aquello asociado con las técnicas de control. Se pasa del control de los cuerpos individuales al control de la "población" o "de la vida", del "hombre-especie", esa "masa global, afectada por procesos de conjuntos que son propios de la vida como el nacimiento, la muerte, la producción, la enfermedad, etc. (...) una 'biopolítica' de la especie humana" (2000 [1976]: 220).

Buena parte de estas tecnologías o dispositivos de seguridad que trabajan sobre todo, a partir de un cálculo estadístico de probabilidades, suponen la "reactivación" y "transformación de las técnicas jurídico-legales [como la técnica de las fronteras] y de las técnicas disciplinarias [como la técnica celular o de reclusión en una celda]" (Foucault, 2009: 23). A su vez, "la seguridad", afirma Foucault, "es, antes bien, una manera de sumar, de hacer funcionar, además de los mecanismos de seguridad propiamente dichos, las viejas estructuras de la ley y la disciplina" (2009: 26).

Foucault analiza una "historia de las tecnologías de seguridad" que comienza por "algunos rasgos [y cuestiones] generales de esos dispositivos de seguridad”. El primero de ellos involucra el problema del espacio -que, por su vínculo directo con las relaciones de poder, yo reconocería también como el problema del territorio-. Paralelamente, el autor hablará del "tratamiento de lo aleatorio", de la "normalización específica de la seguridad" y del surgimiento, no solo de la noción sino también de la "realidad de la población" (2009: 27). El Estado pasa a preocuparse por el conjunto de su territorio (el poder estrictamente soberano) y luego, por el conjunto de su población (el biopoder). Con el crecimiento de la urbanización, la ciudad y su "formato de cuadrícula" (que, en otras palabras, es un modo de ordenamiento), se convierten en un modelo de organización territorial y administrativa del Estado.

Foucault se referirá a problemas directamente ligados al espacio y, más específicamente a la ciudad, como las enfermedades (da el ejemplo de la epidemia del cólera en Europa a partir de 1830), o las revueltas urbanas que también afectaron al continente en el mismo período. Hasta el siglo XVIII y en el inicio del siglo XIX, la ciudad era todavía una entidad jurídica y administrativa aislada en relación a otros espacios, caracterizada por "el encierro dentro de un espacio amurallado y estrecho", bastante heterogénea en relación al campo. Su crecimiento y la intensificación del comercio pusieron en jaque estas características. Cabía así "resituar la ciudad en un espacio de circulación" (2009: 29). Ese fue el gran problema analizado por el historiador Jean-Claude Perrot en la ciudad de Caen en el siglo XVIII.

A través del ejemplo de la ciudad de Richelieu, inspirada en el modelo del campamento militar (romano), Foucault acaba corroborando, aunque de un modo un poco superficial, su distinción entre poder soberano y poder disciplinario, especialmente del ejército. El primero ejerciéndose sobre la capitalización de un territorio (la ciudad pensada a partir de un macrocosmos mayor que ella) y el segundo, sobre la arquitectura de un espacio, de un edificio. De este modo, y de forma diferente al poder soberano, en el marco del 
poder disciplinario la ciudad sería pensada a partir de una territorialidad menor que ella, "una figura geométrica que es una suerte de módulo arquitectónico", afirmará él -y sin duda, a partir de otras modalidades de muros-. Es como si los muros hubiesen sido erradicados de las fronteras de la ciudad, en su separación de los peligros del campo e introyectados, incorporados en su lado interno, no sólo separando y segregando los peligros (y a las clases peligrosas) en su interior, sino también auxiliando en la clasificación y ordenación de sus potencialidades.

Mediante el tercer ejemplo, la reforma de Nantes en el siglo XVIII, Foucault demuestra la fuerza de la cuestión de la circulación -dentro y fuera de la ciudad- en sus adyacencias y con la capital, Paris, acompañada por la cuestión de la vigilancia, que sería exacerbada a partir de la supresión de las murallas. Otra problemática que comienza a quedar clara es la integración de la visión territorial futura en los proyectos urbanísticos, de los futuros despliegues de la expansión urbana, enfatizándose así el tema de la previsión y de las probabilidades.

Mientras que la ciudad disciplinaria buscaba organizar claramente un (nuevo) orden territorial, inclusive en espacios vacíos y artificiales como en Richelieu, la ciudad de la seguridad -o biopolítica- trabajará sobre el orden ya existente, enfrentará sus limitaciones, maximizando los elementos positivos, la buena circulación y minimizando los riesgos, preocupándose con probabilidades. Como afirma Giorgio Agamben:

Mientras el poder disciplinario aísla y cierra territorios [ofreciendo aquí una noción mucho más amplia de territorio que Foucault], las medidas de seguridad llevan a una abertura y a la globalización; mientras la ley quiere prevenir y regular, la seguridad interviene [concretamente] a través de procesos continuos, con el fin de dirigirlos. En pocas palabras, la disciplina quiere producir orden, la seguridad quiere regular el desorden (2002: 145).

Foucault considerará el problema de la seguridad, "en el fondo", como el "problema de la serie, serie indefinida de los elementos que se desplazan" (2009: 39), de los carros a los transeúntes, de los ladrones a las mismas, todos ellos inmersos en una estimación de probabilidades. Para caracterizar el espacio típico de la acción de los mecanismos y dispositivos de seguridad, el autor apela a la noción de "medio". A partir de buscar los orígenes de la utilización del término en la biología (con Lamarck) y en la física (con Newton), define al medio como "lo necesario para explicar la acción a distancia de un cuerpo sobre otro (...) el soporte y el elemento de circulación de una acción" (2009: 40-41). Aun cuando los urbanistas del siglo XVIII no usaran el término, serían los primeros en tomar en cuenta "el esquema técnico de ese concepto" (2009: 41). Así, la modalidad de poder que se instituye a través de la seguridad, se relaciona con la cuestión de la población "una multiplicidad de individuos que están y solo existen profunda, esencial, biológicamente ligados a la materialidad dentro del cual existen", que es también, más allá de la "masa" y del conjunto de sus cuerpos (disciplinarios), su "medio" (2009: 42).

Esta contextualización histórica de las modalidades de poder, a partir de la urbanización -con mayor o menor evidencia de los territorios-muro- sirve como fundamento para analizar, ahora de modo más específico, aquellos que considero uno de los dispositivos territoriales de poder más difundidos. Tal vez, la forma más conocida de espacio 
Muros como tecnologías y dispositivos territoriales...

ROGÉRIO HAESBAERT

amurallado esté asociada a la ciudad medieval de Europa Oriental modelo que, aunque bastante reformulado, ha sido también difundido en el proceso de colonización americano. ${ }^{3}$ Sin embargo, los muros, las murallas o cercos, no solo no se restringieron al mundo medieval, sino que también tuvieron funciones a lo largo de la historia. En el caso del mundo moderno, obedecieron al juego que tuvo lugar entre diferentes modalidades de poder y a las que estaban prioritariamente vinculadas.

En oposición a la lectura foucaultiana que restringe el uso del término territorio a la identificación del espacio bajo el dominio del poder soberano del Estado moderno, es decir, a la jurisdicción de su soberanía, propongo que las tres principales modalidades o dimensiones de poder identificadas por Foucault y anteriormente abordadas -el poder soberano, el poder disciplinario y el biopoder- se corresponden con la construcción de procesos de des-territorialización, cada uno con sus características propias, dependiendo del predominio de una de aquellas modalidades. Así, identificamos de forma simplificada, los macroterritorios estatales bajo el dominio de poder soberano, los microterritorios disciplinarios bajo dominio del poder disciplinario, y el medio o territorios-red, bajo el predominio del biopoder. Siguiendo este razonamiento, una misma forma espacial como el muro, puede adquirir distintas funciones y significados (insertos en distintos procesos de dominación y apropiación del espacio) de acuerdo a la modalidad de poder a la cual este estaría prioritariamente relacionado. Esto quiere decir que su significado, va más allá de su simple función material, debiendo ser analizado también como referente para la difusión de un poder en su dimensión simbólica.

Ante todo, la cuestión que se plantea es ¿̇cómo una misma tecnología de poder, muy semejante en su forma de manifestación física, puede estar presente en diferentes tipos de sociedad, bajo distintas combinaciones de relaciones de poder, y cuál es la función y/o sentido que ella adquiere en estos diversos contextos geohistóricos?

Comencemos retomando algo obvio: no es el muro en tanto construcción física que, por sí solo, representa un territorio (aunque su modalidad más típica pueda ser así presentada), sino las diversas relaciones sociales y de poder que este incorpora o de las cuales este se convierte en un elemento constitutivo. De esta manera, consideremos el muro desde una concepción relacional de territorio y, por lo tanto, inmerso en procesos de des-territorialización. En lo que se refiere a las relaciones sociales de poder reproducidas allí, lo que realmente importa es saber quién controla a quién a través del espacio.

Si tomamos como referencia a David Harvey (2012) podemos afirmar que, aunque una visión estancada, absoluta, del espacio esté siempre presente en nuestras concepciones del territorio y, aunque ella sea criticable, tiene un papel a cumplir. Sin embargo, se debe privilegiar el carácter relacional, el territorio visto a partir del conjunto de vínculos de poder que, al mismo tiempo, producen y son producidos por el espacio. Estas relaciones de poder son, por lo tanto, inherentes a la producción y configuración de ese espacio.

$3 \mathrm{Al}$ respecto ver, por ejemplo, el trabajo de carácter conjetural e inédito, de análisis y mapeamiento del muro de los inicios de la ciudad de Rio de Janeiro (1568), durante el corto período que ocupó "a la manera de una acrópolis" el alto de la colina ("outeiro") de São Sebastião. Elaboración del geógrafo Mauricio de Abreu (2010, especialmente v. II, 231-235). 
Así, el papel territorializador-desterritorializador de los muros, varía profundamente a lo largo de la geografía, de la historia y, claro, de los sujetos y del contexto jurídicopolítico al cual nos estuvimos refiriendo. Además, es muy importante recordar que el muro, como otras formas de límite territorial, participa de los procesos de exclusión e inclusión, de definición mayor o menor, más o menos compleja, del adentro y del afuera. Probablemente su función primera sea la de marcar una determinada diferenciación y/o una cierta interioridad, en un juego múltiple de des-articulaciones.

Sin embargo, la propia configuración física del muro -y no obligatoriamente su forma patrón, de concreto- puede indicar un espacio más abierto o más cerrado, más fijo o más moldeable. Es esto lo que verificamos hoy, por ejemplo, con los cercos de contención a las migraciones, construidos en las fronteras de países de Europa Oriental, y que pueden ser desmontados y desplazados con relativa facilidad, permitiendo adaptaciones de acuerdo a los cambios de dirección del flujo migratorio.

Asociar a los muros con distintas configuraciones o dimensiones del poder -vinculadas a la soberanía, la disciplina y la seguridad o biopoder- facilita la construcción de una tipología, más simplificada (como toda tipología), pero que puede servir como un importante punto de referencia para la construcción de interpretaciones más amplias que permitan aprehender la complejidad del fenómeno. Así, propongo identificar:

" Muros de reclusión o confinamiento. Tanto de reclusión por exclusión permanente como de reclusión por exclusión temporaria (en la medida que existe la posibilidad de contemplar en algún momento la inclusión) de base disciplinaria;

" Muros de articulación o balizamiento. Más sutiles, típicos de la dominación soberano-disciplinar moderna;

» Muros de contención. Producidos para contener y/o reorientar circulaciones, típicos del biopoder, y que pueden aún diferenciarse en muros-represas, muros-ductos o de canalización (aquí es importante distinguir también los muros de auto-contención, formulados en general, por grupos hegemónicos como forma de protección).

Es evidente que, así como sucede con las distintas modalidades de poder, no se trata aquí de tipos de muros mutuamente excluyentes. Como veremos, dependiendo del contexto geohistórico, estos distintos tipos de muros están marcados por profundas intersecciones y ambivalencias. Todos ellos se manifiestan a través de una interrelación compleja de dimensiones, al mismo tiempo funcional y/o, más claramente de dominación, y simbólica y/o, más claramente de apropiación, en los términos lefebvrianos anteriormente comentados.

Empezamos comentando una modalidad que podríamos identificar como de carácter más tradicional de muro. Ella efectivamente representa una separación, con capacidad de vedar el acceso y confinar determinados individuos o grupos sociales. Ella busca establecer la definición de un adentro y una fuera (hoy tan cuestionada), de una inclusión y de una exclusión más claramente diferenciable. Mientras tanto, entre los muros de reclusión o confinamiento, podemos distinguir aquellos de carácter más permanente y aquellos de carácter más efímero. 
Muros como tecnologías y dispositivos territoriales...

ROGÉRIO HAESBAERT

En este sentido, en una relectura de Michel Foucault, Giorgio Agamben habla de dos paradigmas socio-espaciales: el paradigma de la lepra y el paradigma de la peste. El primero es asociado a la exclusión definitiva y representa aquello que denominamos reclusión de exclusión. Según el autor:

(...) requería que los leprosos fueran "situados fuera" de la ciudad. En este modelo, la ciudad pura mantiene al extraño afuera [del otro lado de los muros o aún confinado en otros muros] en lo que Foucault llama le grand enfermement, "el gran encarcelamiento": por lo tanto, encerrar y excluir. Este es el modelo de la lepra (Agamben, 2010).

De modo diferenciado, el paradigma de la peste inaugura los principios de la sociedad disciplinaria, pues:

Cuando la epidemia se instaura en la ciudad, es evidente que no es posible mover a las víctimas de la peste hacia afuera. Por el contrario, se crea por la primera vez un modelo de vigilancia, control y articulación del espacio urbano. Este se divide en secciones y, dentro de cada sección, cada calle se convierte en autónoma, y puesto bajo la vigilancia de un intendente....En fin, un quadrillage [cuadriculado] del territorio urbano vigilado por intendentes, médicos y soldados (Agamben, 2010).

Los muros de esta reclusión temporaria o pasible de volver a ser incluida (el ejemplo típico es el del presidario), y que Foucault prefiere denominar "reclusión por secuestro" (ante la constante posibilidad de "rescate"), acaban estableciendo fuertes enlaces con los muros de articulación de los espacios, que se derivan de aquí, pues:

Así, mientras el leproso era rechazado por un aparato de exclusión, la víctima de la peste es encasillada, vigilada, controlada y tratada a través de una compleja red de dispositivos que dividen e individualizan, y al hacerlo también articulan la eficacia del control y del poder.(Agamben, 2010).

A través de esta mirada enfocada en la realidad europea, Agamben afirmará que "el espacio político de la modernidad, a partir del siglo XVIII hasta hoy, es resultado de la fusión de esos dos paradigmas". Se pasa así de una visión binaria (enfermo/sano, loco/ no loco, normal/anormal), a una "complicada serie de distribuciones diferenciales de dispositivos y de tecnologías que subjetivan, individualizan y controlan a los sujetos" y que constituiría "un primer esquema" a los fines de definir el actual espacio metropolitano. En este contexto y, habiendo alcanzado ahora una sociedad moldeada sobre todo por el biopoder y por las cuestiones de seguridad, vemos:

(...) la imposibilidad de definir unívocamente los confines, las murallas, la espacialización, [la territorialización, podemos decir], justamente porque estos son el resultado de la acción de este paradigma doble: ya no es más una simple división binaria, sino la proyección sobre esta división de una compleja serie de procedimientos y tecnologías individualizantes y articuladoras sobre esta división (Agamben, 2010). 
Mientras que las sociedades disciplinarias típicas combinaban remanentes de la reclusión excluyente (el paradigma de la lepra) con la reclusión mayoritaria, que contemplaba la posibilidad de volver a incluir (o inclusión excluyente del paradigma de la peste), y aún creían en la conformación de un orden territorial, la compleja serie de tecnologías territoriales biopolíticas inaugura nuevos procesos que denominamos de contención territorial. La contención está marcada por la exclusión inclusiva, en la ambigüedad de adentro y de afuera, de lo legal y de lo ilegal, de lo público y de lo privado.

Aquí se debe tener cuidado de no confundir los muros construidos por una especie de auto-contención, deliberadamente propuestos para la protección, de los que se encuentran en su interior, como en el caso de los condominios cerrados y los muros efectivos de contención. Estos últimos son aquellos impuestos desde afuera a grupos que así, sufren una especie de coacción territorial en su movilidad. Cabe destacar que, entre estas distintas situaciones, las fronteras no siempre resultan claras, como se observa en el caso de las propuestas que se dan al interior de las favelas y que, de alguna manera, copian el modelo de los condominios cerrados, a partir de la construcción de muros o de la contratación de seguridad privada.

En este sentido, Giorgio Agamben nos ayuda a identificar una primera modalidad de muros de contención biopolítica, al definir la configuración del campo, espacio "de excepción" (donde las leyes de la excepción se convierten en regla), marcado por la indefinición entre el adentro y el afuera del Estado y de la ley, y donde lo provisorio puede convertirse en permanente; como en los campos de refugiados o en los acampes de los sin tierra en Brasil, que pueden mantenerse por décadas.

De esta manera, podríamos hablar de un paradigma biopolítico del "campo" en sus diversas modalidades y grados de ambivalencia. Por ejemplo, el campo del control de los migrantes o algunas favelas en momentos de conflicto, donde no se define claramente el pertenecer efectivo a la jurisdicción del Estado o a otros circuitos de poder (como el asistencialismo de las Ongs o el autoritarismo ambiguo del narcotráfico). Allí, por ser regla, lo ilegal puede ser considerado legal, o puede darse -como se vive en muchas favelas- el paso facilitado, la convivencia o aún la indisociabilidad, entre territorialidades legales e ilegales. Fácilmente se pasa de uno a otro, muchas veces, hasta como única garantía de la sobrevivencia. A este tránsito frecuente también lo denomino de transterritorialidad (Haesbaert, 2014).

Sin embargo, tal vez, los muros más típicos de contención sean aquellos que, sin pretender (o conseguir) cerrar espacios, constriñen o (re) orientan la expansión y/o la movilidad. Son los actuales muros fronterizos internacionales o los de algunas favelas (figuras 1 y 2) y de las grandes vías de circulación -como la Linha Vermelha 4 (figuras 3 y 4) en el caso de Río de Janeiro-. Como diría Foucault, se trata de valorizar, seleccionar y/o reorientar las "buenas" y las "malas" circulaciones. Lo que está en juego en primer lugar, es el problema de la expansión y de la movilidad -y hasta de la visibilidad- de ciertos grupos. Más que aislar o confinar, estos muros balizan y/o ayudan a monitorear

4 Nombre popular que se le da a la Autopista Presidente João Goulart que une los municipios de Rio de Janeiro y de São Joao de Meriti, atravesando también el municipio de Duque de Caxias y después se conecta con la "Via Dutra", que une Rio y San Pablo (N. de la T.). 
el desplazamiento y/o la expansión geográfica de ciertos grupos sociales; en suma, como manifiesta Agamben, "regulan el desorden" instituido que, bajo una perspectiva distinta, podrían ser leídos como otro tipo de orden o contraorden.

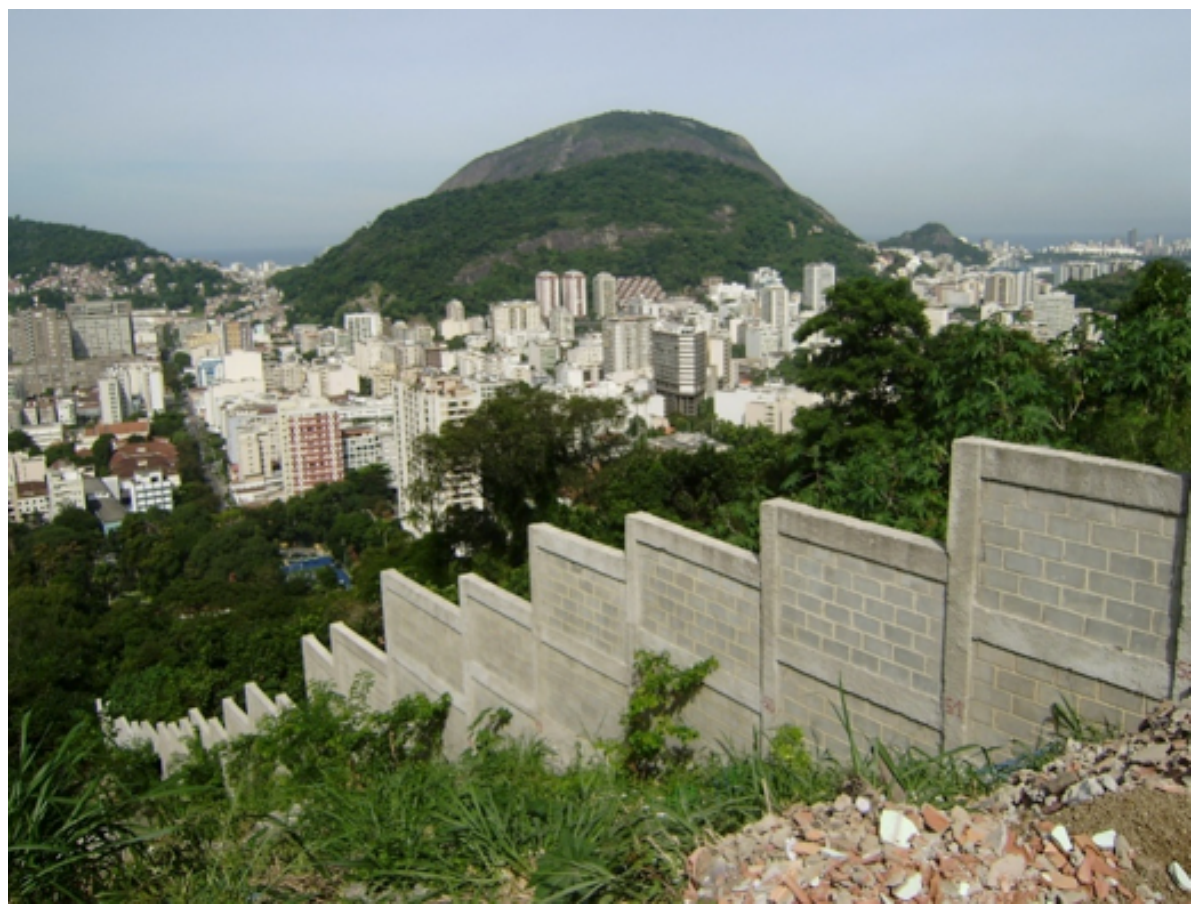

Figura 2. El muro en la favela Santa Marta, Rio de Janeiro, al fondo el barrio de Botafogo. Fuente: Fotografía del autor

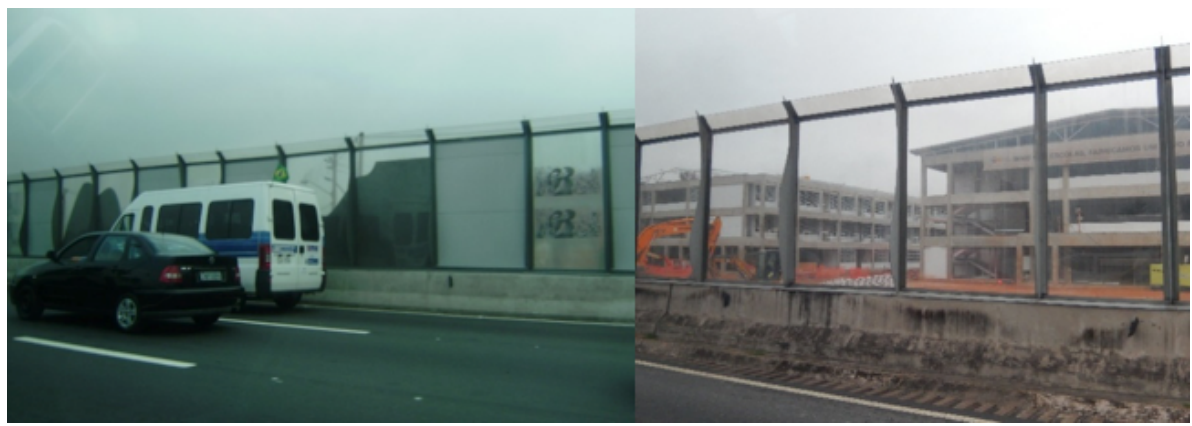

Figuras 3 y 4. Muro de la Linha Vermelha, en Río de Janeiro. Se pueden identificar distintos regímenes de visibilidad: opaco para la favela y transparente para el proyecto escolar del Estado. Fuente: Fotografías del autor.

Estos muros pueden tener la función primera de obstaculizar la movilidad, como los muros-represa de muchas fronteras internacionales, o de canalizar, como los murosductos de grandes arterias de circulación, o pueden presentarse con ambas características, como en el caso de la Linha Vermelha, en Rio de Janeiro. Así, al mismo tiempo que se canaliza el tráfico entre el aeropuerto internacional y las zonas centro y sur de la ciudad, el muro impide la circulación (y la propia visibilidad) del espacio de los habitantes de las favelas, prácticamente sin conexión directa con la autopista. Aunque el argumento biopolítico de la barrera acústica y de la disminución de los casos de 
Muros como tecnologías y dispositivos territoriales... ROGÉRIO HAESBAERT

muertes de peatones hayan sido argumentos bastantes difundidos, los documentos originales de la formulación del proyecto, elaborados por políticos, explicitaban que una de las principales justificaciones para su construcción era la cuestión biopolítica de la seguridad -como si el espacio más afectado por la violencia y, por lo tanto, a ser protegido, no fuese la favela sino la autopista-.

Los muros internacionales, que todavía identifican los territorios de la soberanía estatal y que, paradójicamente, nunca proliferaron tanto como en nuestros días (principalmente después del 11 de setiembre de 2001), también son representativos de la ambivalencia de la contención biopolítica. Al mismo tiempo en que parecen revelar un reforzamiento del poder soberano, del papel del Estado en su control sobre el territorio y su población, parecen estar manifestando justamente su fragilidad. Frente a la incapacidad de ejercer un control efectivo sobre la mayor parte de los flujos, el Estado exhibe, por lo menos a través del muro, un referente simbólico que alimenta la imagen según la cual este posee la capacidad de actuar.

Según Wendy Brown (2009, 2015[2010]), el muro tiene una función más simbólica o "teatral" que concreta, procurando probar, especialmente a la porción de la población de mayor poder de demanda en términos de seguridad, que el Estado actúa, aun cuando esté demostrada la ineficacia de esta tecnología o dispositivo territorial de control. Para la autora hay una especie de exigencia de límites "en un universo que perdió demasiado sus horizontes". De esta manera, el muro, produce un "nosotros" (debilitado) que objetiva remediar la crisis político-identitaria nacional:

(...) los muros resucitan [las identidades] bajo los planos ópticos y síquicos, proyectando la bondad sobre los dominantes (víctimas) y la hostilidad, la violencia, la perfidia o la codicia sobre los dominados (Brown, 2009: 191).

Está en juego aquello que la autora denomina las "garantías psíquicas o paliativas" que los muros proporcionarían, en medio de las pérdidas de soberanía y de la pretendida seguridad estatal, ahora substituida por "las fantasías de la inocencia, protección, homogeneidad y autosuficiencia” (Brown, 2015: 156).

La fuerza simbólica incorporada en la producción contemporánea de muros, aparece tanto entre fronteras internacionales (donde probablemente los casos más evidentes, son los muros entre Israel y Palestina y entre Estados Unidos y México), como entre barrios al interior de las ciudades (tal es el caso de las propuestas polémicas en barrios pobres en Argentina y Perú, o aquellas otras pensadas para barrios gitanos en la República Checa, sin hablar de ejemplos más antiguos, como los muros de Nicosia en Chipre, y de Belfast en Irlanda del Norte).

Este sentido simbólico de los muros, directamente ligado a la cuestión de la seguridad y del miedo, debe distinguirse de otra modalidad bastante diferente. Se trata de los muros que proponemos llamar muros-patrimonio, vinculados a las políticas de patrimonialización del espacio. En este caso, la dimensión simbólica en juego no habla del rechazo o segregación de los grupos, sino de su atracción (por lo menos para aquellos que pueden pagar por el acceso a los mismos), ya que se trata de un proceso especialmente vinculado a actividades turísticas capitaneadas por el Estado y/o por empresas privadas. 
Entre estos muros-patrimonio existen aquellos de carácter histórico, parcialmente transformados también en sitios arqueológicos, que son restaurados a los fines de vender una imagen, un paisaje y convertirse en atractivos turísticos. Además del caso más famoso de la muralla China, uno de los muros del mundo hoy más visitados, existen casos menos conocidos, como el muro Danevirke de cerca de 30 kilómetros de extensión, situado en el norte de Alemania (casi en la frontera con Dinamarca) o los restos de los limes, los muros-límites del Imperio Romano, con varios tramos que se conservan en países como Alemania. El más conocido de ellos, el muro de Adriano, se sitúa en el norte de Inglaterra, casi en la frontera con Escocia.

Esta evidente afirmación simbólica de las murallas, tanto en el pasado como en la actualidad, a diferentes escalas, nos lleva también a reconocer que, más allá de su materialización, existen también los llamados muros invisibles. Estos poseen una carga simbólica compleja y relacionada con el momento histórico, el espacio cultural y la escala en que son concebidos. Aunque no sean objeto de nuestro análisis, ya que hemos priorizado su abordaje como tecnología de control y espacio de referencia simbólica, reconocemos que estos muros invisibles precisan ser debidamente denominados e investigados.

Es importante percibir que los muros contemporáneos, ligados a la problemática de la seguridad biopolítica, complejizan la relación propuesta inicialmente, entre territorios marcados por los procesos de dominación (más concreta) y aquellos caracterizados por dinámicas de apropiación (más simbólica). Específicamente, en el caso de los muros fronterizos de contención (especialmente de migrantes), la dominación tiene lugar muchas veces más a través del poder simbólico que estos referentes espaciales condensan (en nombre de la acción estatal contra los peligros que vendrían de afuera), que por sus efectos más concretos y directos.

Su condición de tecnología de poder, ligada a procesos de dominación, es indiscutible. En un sentido amplio (y no necesariamente negativo), el "espacio de dominio" es fruto, según Lefebvre, de "un espacio natural transformado (mediatizado) por una técnica y una práctica". En el mundo moderno, por la "tecnicidad", "la dominación del espacio deviene -si osamos plantearlo- completamente pre-dominante". Esta dominación, muy antigua en la historia, proviene del poder político en sentido estricto:

La arquitectura militar, las murallas y fortificaciones, los trabajos de encauzamiento e irrigación, muestran los abundantes y finos ejemplos del espacio dominado. Tales espacios son labores de construcción [ouvrage] más que obras [oeuvre], ni siquiera "producto" en la acepción estricta, moderna e industrial; el espacio dominante es el resultado de los proyectos de un amo.... El espacio dominado es generalmente cerrado, esterilizado, vacío (Lefebvre, 2013: 213).

Como en el caso de los muros propuestos a través de las políticas públicas planteadas de arriba para abajo, sin consulta a las prioridades de las comunidades afectadas (como es el caso de los muros junto a las favelas de Rio de Janeiro), la dominación del espacio impone una geometría ajena a aquella construida por los propios habitantes en su espacio vivido. Como afirma Lefebvre, "para dominar un espacio, la tecnología introduce en un espacio anterior una forma, muy a menudo una forma rectilínea, rectangular (el entramado, la cuadrícula)" (2013: 213). 
De esta manera, y desde la lectura territorial amplia inicialmente propuesta, los muros involucran a niveles diferentes, un proceso de dominación a través del control físico (hoy profunda pero no totalmente cuestionado) y un control simbólico. Como ha destacado Wendy Brown (2015), su simple visibilidad debe ser ampliamente considerada. Claro que no se trata apenas de su visibilidad en un sentido amplio que hace que, por ejemplo, la acción del Estado sea extensamente publicitada (la propaganda de estar haciendo algo en relación a la seguridad). Se trata también de explorar el juego que puede darse, concretamente entre aquello que el muro deja ver y aquello que invisibiliza.

Esto queda demostrado a través del muro de material sintético (plástico) de la Linha Vermelha, en Río de Janeiro, ya mencionado. Una remodelación reciente modificó el tipo de visibilidad proporcionada por el muro; contrariamente al resto del trayecto junto al área de la favela-, el muro se convirtió en transparente frente al gran proyecto estatal de la Escola do Amanhã (Escuela del Mañana, figura 3). Esto implicó aplicar dos regímenes de visibilidad opuestos dentro de un mismo aparato técnico (el muro): ocultamiento de la favela, exhibición del proyecto estatal.

Es importante resaltar que los ejemplos de muros aquí trabajados, prácticamente fueron construidos a partir de una perspectiva del poder hegemónico. En este sentido, del mismo modo en que se constató que la desterritorialización no es buena o mala en sí misma, el muro en sí, obviamente no tiene un sentido negativo de dominación y/u opresión. Precisamos también de muros o, por lo menos, explicitar los límites físicos para organizar nuestra vida. Como señalamos en un debate sobre límites y fronteras (Haesbaert, 2016), nuestra existencia está también moldeada por el ir y venir entre fijación y movilidad, orden y desorden, definición y superación de límites.

En el caso del discurso de la in-seguridad que acompaña a la mayor parte de los proyectos de muros contemporáneos, como ya comentamos, aún los habitantes de las favelas, algunas veces recurren a cierres y a seguridades privadas, en una especie de imitación del patrón de condominios cerrados de las clases hegemónicas. En el caso mejicano, encontramos hasta municipalidades autónomas que, si bien no llegan a construir muros, establecen puestos o garitas militarizadas en sus principales vías de acceso, como forma de protección y seguridad, frente a la explotación ilegal de sus bosques y ante la violencia del narcotráfico. Esto sucede, por ejemplo, desde el año 2011 con la comunidad indígena de purépecha, situada en el municipio de Cherán (Estado de Michoacán) que visité en agosto de 2016 (figura 5). Una cuestión que merece un debate más amplio que tome en cuenta no solo los muros, sino también las barreras físicas en sentido general (al respecto ver Povoa Neto 2010 y Rosière, 2015). 


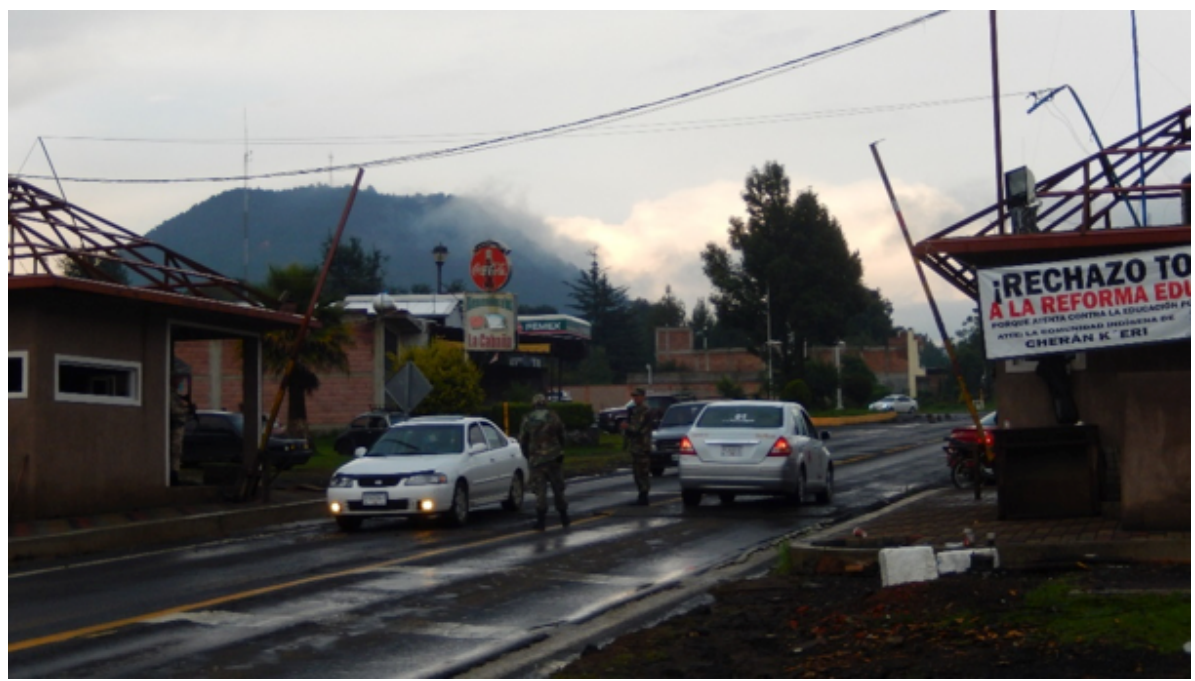

Figura 5. Puestos de control en una de las rutas del municipio autónomo de Cherán, estado de Michoacán, México. Fuente: Fotografía del autor.

Además de constatar el carácter ambivalente de los muros, precisamos hacer mención también, aunque sea brevemente, a las formas de rodear o de superar el muro en tanto obstáculo (aun cuando ineficaz) a la movilidad. Inspirado en otros autores (como Fresia [2004] y Telles da Silva [2010]), denominó a estos procesos de "contorneamiento" (Haesbaert, 2014). Especialmente en el caso de los muros de contención territorial, como aquellos construidos a lo largo de las fronteras internacionales en las últimas décadas, resultan evidentes las estrategias de los diferentes grupos sociales migrantes para rodear estos obstáculos físicos, ya sea intentando pasar por encima o por debajo de ellos (a través de túneles, como los construidos en la franja de Gaza o en la frontera de México con Estados Unidos), ya sea buscando otra ruta cuya trayectoria evite las fronteras amuralladas (como sucede con las Islas Canarias, España, contrapunto de los muros construidos por ese país en sus enclaves marroquíes en Ceuta y Melilla).

La posibilidad siempre abierta, de contornear los muros biopolíticos (o de seguridad), contrariamente a los muros de reclusión, configura una especie de revés de la contención territorial. El contorneamiento territorial es la otra cara de la ambivalencia de los muros de contención. Cabe destacar también, que el término contención, a diferencia del de reclusión, obligatoriamente implica esa posibilidad de subvertir la pretendida fijación del orden instituido por los muros. Siempre se trata de un efecto represa-como un dique, se estanca el flujo por un tiempo, pero luego este podrá encontrar otro camino, fluir por otro lado, o aún más, a partir de una presión vertical, pasar por encima del dique de la represa-. Este constante contornear de los muoros, a través de la búsqueda de otras trayectorias alternativas, lleva a los propios Estados a adaptar sus tácticas a partir de construir barreras más flexibles, como los cercos de alambre maleables (y transportables sin dificultad) ya mencionados, levantados en la actualidad en las fronteras de los países de Europa del Este. En la medida que los migrantes encuentran fácilmente otros trayectos, estos cambios pueden ir acompañados de la alteración en la posición y distribución de los dispositivos de contención. 


\section{Desdoblamientos y para (no) concluir}

Más allá de las derivaciones posibles, por ejemplo, en relación a la proyección simbólica de los muros, dejamos como referencia para otras investigaciones la cuestión del territorio-muro y los procesos de des-territorialización en relación a la especificidad de nuestra realidad latinoamericana y brasilera. Nos preguntamos, por ejemplo, chasta qué punto estos muros, tal como han sido interpretados por la lógica foucaultiana, explícitamente eurocéntrica, encontraron y encuentran una singularidad en la configuración de nuestros espacios decoloniales, en el pasado y en la actualidad? ¿Por qué, al mismo tiempo en que los muros fronterizos proliferan en el interior de nuestras ciudades, son (aún) poco frecuentes en nuestros límites fronterizos internacionales (a excepción de aquel impuesto por los Estados Unidos a México)?5

De todos modos, y para cerrar, creemos que es necesario recuperar la idea de que, la conceptualización del territorio aquí propuesta, no se restringe a la perspectiva funcional de carácter concreto y técnico, y que en el caso de los muros acaba siendo la dimensión priorizada. Reconocemos que el abordaje que concibe al territorio como una tecnología política, principalmente a partir del influyente trabajo del geógrafo inglés Stuart Elden, es dominante en la actual geografía anglosajona. Tal vez, la gran contribución a este debate que proviene de las llamadas geografías latinas, sea justamente el de destacar la fuerza del poder simbólico accionado en la construcción del territorio en sentido amplio, estén estos amurallados o no, sean estos hegemónicos o subalternos.

Como vimos, el muro no es simplemente una tecnología, una organización arquitectónica. Este involucra toda una red discursiva que hace referencia a sus propósitos y efectos (abordaje que precisa ser desarrollado de modo más extenso) y que, muchas veces, acaba siendo más estratégico que su construcción material o que los flujos concretos que localmente persigue controlar. Foucault destaca también el juego de reinterpretaciones de las que pueden ser objeto las prácticas involucradas en la creación de un dispositivo - como en nuestro caso, el muro- y que pueden provocar "cambios de disposición, modificaciones de funciones", siempre dentro del papel estratégico que se le otorga, y que se orienta a responder a una urgencia. Sin duda, en principio, los muros contemporáneos "responden a una urgencia", y de forma bastante genérica, esta urgencia tiene que ver con la contención de las movilidades o de circulaciones no deseadas. Sin embargo, el riesgo representado por los sujetos en la mira, queda circunscripto al campo de la sospecha.

Otra especificidad que poseen los muros de nuestro tiempo, es su permanente conjugación con otras formas de control, principalmente con las distintas modalidades de televigilancia -sea en su forma fija, sea en su forma móvil (mediante satélites o drones)En un mundo tan sofisticado en términos de tecnologías de control, la singularidad del muro, y de su papel, reside sobre todo en la imposición de su materialidad. Su visibilidad material, proyectada de modo referencial, acaba teniendo amplios efectos como símbolo de un control y de un poder que, si dependiese solo de la funcionalidad del muro, no sería tan eficaz.

5 En el momento de la redacción de este artículo, tomé conocimiento de la construcción de un muro propuesto por Argentina en su frontera con Bolivia, y de otro, que se sitúa no necesariamente en la frontera, pero sí a lo largo de la vía de acceso al puente entre Posadas en Argentina y Encarnación en Paraguay. 
A partir de recordar nuestra definición del territorio, tanto como dominación (poder político-económico con sus efectos más concretos) como apropiación (poder simbólico) y su uso como categoría de la práctica, especialmente en el contexto latinoamericano, constatamos que el territorio está también profundamente involucrado en las estrategias de autonomización subalterna. De nada serviría una bella y ajustada ${ }^{6}$ teoría sobre el territorio, si ella ignorase el potencial instrumental que esta noción puede cargar en la promoción de las luchas por mayor afirmación y autonomía de los grupos subalternos.

En el caso de los territorios-muro, esto implica no solo la investigación -y el combatedel muro como instrumento de dominación y control social, sino también el reconocimiento del potencial, no necesariamente del muro en sí sino de otros tipos de barrera, como mecanismo de defensa y de organización/apropiación de grupos subalternos. Es claro que este razonamiento incorpora los procesos que denominamos de contornamiento de los muros, como ocurre frecuentemente con los inmigrantes que acaban buscando otros caminos para llevar a cabo sus trayectorias. En este juego múltiple y complejo de poder es que en este artículo se propuso la idea del territorio-muro. Ella fue pensada no solo como una simple tecnología política sino, más bien, como un dispositivo de poder. Desde una mirada latinoamericana, el territorio no ha sido solo un instrumento normativo hegemónico o una categoría analítica de investigación, sino también una conceptualización a través de la cual vehiculizamos nuestro inconformismo, nos empoderamos en el tránsito por territorialidades múltiples y, más allá de los muros que segregan y oprimen, construimos nuestras propias concepciones -recomponiendo constantemente los límites- de nuestra vida en comunidad.

Traducción al español de Perla Zusman.

6 . "enxuta" en el texto original (N. de la T.) 


\section{Q Bibliografía}

»Abreu, M. (2010). Geografia Histórica do Rio de Janeiro (1502-1700). Rio de Janeiro: Andrea Jakobson Estúdio Editorial.

» Agamben, G. (2014 [2007]). O que é um dispositivo \& 0 amigo. Chapecó: Argos.

» Agamben, G. (2010 [2006]). Metropolis. Recuperado de http://www. culturaebarbarie.org/sopro/verbetes/metropolis.html

" Agamben, G. (2002). Sobre a segurança e o terror. En: G. Cocco y G. Hopstein (Org.) As multidões e o império: entre globalização da guerra e universalização dos direitos (pp. 145-147). Rio de Janeiro: DP\&A.

» Bourdieu, P. (1989). O Poder Simbólico. Lisboa y Río de Janeiro: Difel y Bertrand Brasil.

» Brown, W. (2015 [2010]). Estados amurrallados, soberanía en declive. Barcelona: Herder.

》Brown, W. (2009). Murs: les murs de separations et de décline de la souveraineté étatique. París: Les Prairies Ordinaires.

»Deleuze, G. y Guattari, F. (1994 [1980]). Mil mesetas. Valencia: Editorial Pre-Textos.

》Droit, R.-P. (2008). "Soy un artificiero". A propósito del método y la trayectoria de Michel Foucault. En: Entrevistas con Michel Foucault. Buenos Aires: Editorial Paidós.

" Elden, S. (2013). The birth of territory. Chicago: Chicago University Press.

»Escobar, A. 2015. Territorios de diferencia: la ontología política de los "derechos al territorio". Cuadernos de Antropología Social, 41, 25-38.

»Foucault, M. (1985 [1979]). Microfísica do Poder. Río de Janeiro: Graal.

» Foucault, M. (2000 [1976]). Defender la sociedad. Buenos Aires: Fondo de Cultura Económica.

» Foucault, M. (2009 [2004]). Seguridad, Territorio y Población. Buenos Aires: Fondo de Cultura Económica.

"Fresia, M. (2004). "Frauder lorsqu' on est réfugié". Le Dossier Globalisation et illicite en Afrique. Politique Africaine, 93, 63-81.

" Gottman, J. (1952). La politique des États et sagéographie. París: Armand Colin.

» Gottman, J. (1973). The significance of territory. Charlottesville: The University Press of Virginia.

» Haesbaert, R. (2011 [2004]). El mito de la desterritorialización. Del fin de los territorios a la multiterritorialidad. México: Siglo XXI.

» Haesbaert, R. (2014). Viver no limite: território e multi/transterritorialidade em tempos de in-segurança e contenção. Rio de Janeiro: Bertrand Brasil.

» Haesbaert, R. (2016). Limites no espaço-tempo: a retomada de um debate. Revista Brasileira de Geografia, 61(1), 5-20. 
"Harvey, D. (2012 [2006]). Espaço como palavra-chave. GEOgraphia, 12(28), 8-39.

Lefebvre, H. (1969). El derecho a la ciudad. Barcelona: Península.

Lefebvre, H. (1989). La production de l'espace. París: Anthropos.

Lefebvre, H. (2013). La producción del espacio. Madrid: Capitan Swing.

Massey, D. (2008). Pelo Espaço. Rio de Janeiro: Bertrand Brasil.

»Póvoa Neto, H. (2010). Barreiras físicas como dispositivos de política migratória na atualidade. En: H. Povoa Neto et al. (Orgs.). A experiência migrante: entre deslocamentos e reconstruções (pp. 491-520). Rio de Janeiro: Garamond e Faperj.

» Raffestin, C. (2013 [1980]). Por una geografia del poder. Zamora: El Colegio de Mixoacan.

》 Rosière, S. (2015). Mundialização e teicopolíticas: análise do fechamento contemporâneo das fronteiras internacionais. Boletim Gaúcho de Geografia, 42(2), 369-388.

» Sack, R. (1986). Human Territoriality. Cambridge: Cambridge University Press.

»Santos, M. (2000 [1996]). La naturaleza del espacio. Barcelona: Ariel.

"Telles da Silva, V. (2010). As cidades nas fronteiras do legal e ilegal. Belo Horizonte: Argumentum.

Rogério Haesbaert / rogergeo@uol.com.br

Doctor en Geografía Humana por la Universidad de San Pablo, con estudios posdoctorales en la Open University (Inglaterra). Entre sus numerosas publicaciones se destacan los libros El mito de la desterritorialización (traducido al idioma español y publicado por Siglo XXI Editores), Regional-global: dilemas da região e da regionalização na geografia contemporânea (Bertrand Brasil) y Viver no limite (Bertrand Brasil). 